\title{
Availability of anions in the growth medium to roots of an actively growing plant
}

\author{
H. van Keulen, N. G. Seligman', J. Goudriaan
}

Department of Theoretical Production Ecology, Agricultural University, Wageningen, the Netherlands

Accepted: 17 January 1975

\section{Summary}

Analysis of anion transport to the root of an actively growing plant with a normally dense root system showed that virtually the whole of the anion store in the rooting zone is available to the plant within a few days at the most. Transport by diffusion only is enough to account for most of the depletion, but mass flow will speed up the process. The effcet of mass flow will be considerable in soils with a high dispersion coefficient (loess), but very small in soils with a low dispersion coefficient (clay and sand).

A rule is proposed to determine whether a given root density is sufficient to supply the nitrogen and water needs of the plant by diffusion only.

\section{Introduction}

Transport of ions in the growth medium to roots of plants is so well studied a subject that there would appear to be very little to add (Nye, 1969; Tinker, 1969). The processes of ion diffusion and mass transport are indeed well understood in basic physical terms. The ecological significance of these processes to an actively growing plant has received far less attention. In particular no quantitative treatment of the relative importance of diffusion and mass flow in such a situation comes to mind. The difference between these processes is fundamental to an understanding of ion availability to roots because when transport is by mass flow of water, availability of ions is mainly dependent on concentration; whereas when transport is by diffusion, availability is dependent mainly on root density.

In the treatment offered here, anions only will be considered in order to avoid the complicating processes of exchange between soil solution and the solid phase of the soil. It is relevant to nitrate ions which are the main source of available nitrogen to the plant under many conditions. As nitrogen is quantitatively the dominant 'mineral' element in normal plant tissue, an understanding of the pro-

${ }_{1}$ Present address: Agricultural Research Organisation, Volcani Center, Bet Dagan, Israel. 
cesses that determine its availability is important when the dynamic relations between nitrate availability and plant growth are being studied.

A simple calculation makes it clear that transport by mass flow alone is often inadequate to explain nitrate availability to plants. A crop canopy growing at near optimum rate can increase in dry weight at the rate of $200 \mathrm{~kg} \mathrm{ha}^{-1} \mathrm{day}^{-1}$. If the nitrogen content of the plant is $2.5 \%$ and the transpiration rate is $5 \mathrm{~mm}^{-1 a y^{-1}}$, transport by mass flow alone would mean that the nitrogen concentration of the soil solution must be at least $100 \mathrm{mg} / \mathrm{kg}$. As the nitrogen concentration of the soil water is much lower in most situations, it would appear that diffusion must at least make up the difference. The purpose of this paper is to determine from first principles the potential contribution of diffusion and mass flow to anion availability as a function of root density and anion concentration.

\section{Theoretical background}

The root can be depicted as a cylinder with radius $\mathrm{R}$, surrounded by a growth medium, bounded by half the distance between two roots. A treatment of ion transport by diffusion and mass flow into such a cylindrical system has been given by de Wit \& van Keulen (1972). The basic equations are taken from Crank (1956) and were programmed for numerical solution in CSMP (see Appendix).

Assuming that there are no gradients in the vertical or tangential directions the equation for the diffusion flux per unit area through the wall of a cylinder, surrounding the root, is:

$$
\begin{array}{rlr}
\mathrm{F} & =-\mathrm{D} \frac{\partial \mathrm{C}}{\partial \mathrm{r}}, \text { where } \mathrm{D}=\Theta \mathrm{D}_{\mathrm{o}} \mathrm{L} & \\
\mathrm{F} & =\text { diffusion flux per unit area } & \left(\mathrm{mmol} \mathrm{cm}{ }^{-2} \mathrm{day}^{-1}\right) \\
\mathrm{C} & =\text { concentration of solute } & \left(\mathrm{mmol} \mathrm{cm}^{-3}\right) \\
D_{0}=\text { diffusion coefficient in water } & \left(\mathrm{cm}^{2} \mathrm{day}^{-1}\right) \\
\Theta & =\text { water-filled pore volume } & \left(\mathrm{cm}^{3} \mathrm{~cm}^{-3}\right) \\
\mathrm{L} & =\text { labyrinth factor } & (\text { dimensionless })^{-} \\
\mathrm{r} & =\text { distance from centre of cylinder } & (\mathrm{cm})
\end{array}
$$

To obtain the flux per unit length of root $\mathrm{F}$ must be multiplied by $2 \pi \mathrm{r}$ :

$$
F_{1}=-2 \pi r D \frac{\partial C}{\partial r}
$$

where $F_{1}=$ diffusion flux per unit length $\left(\mathrm{mmol} \mathrm{cm}^{-1}\right.$ day $\left.{ }^{-1}\right)$.

When mass flow also is considered, there are two additional terms in the equation for $\mathrm{F}$ :

$$
\begin{aligned}
F & =-(D+s|v|) \frac{\partial C}{\partial r}+v C \\
v & =\text { rate of water flow in the radial direction }\left(\mathrm{cm} \mathrm{day}^{-1}\right) \\
\mathrm{s} & =\text { dispersion length }(\mathrm{cm}) .
\end{aligned}
$$


The terms $\mathrm{s}|\mathrm{v}|$ describes the dispersion. It must be added to the true diffusion coefficient (Frissel et al., 1970) to give the apparent diffusion coefficient. The term $\mathrm{vC}$ represents the transport by mass flow. While transport by mass flow is dependent on the concentration of anions around the root (or sink), transport by diffusion is dependent on the concentration gradient.

The conservation equation for the radial system, when vertical and tangential gradients are absent, is

$$
\Theta \frac{\partial \mathrm{C}}{\partial \mathrm{t}}=-\frac{\partial \mathrm{F}}{\partial \mathrm{r}}-\frac{1}{\mathrm{r}} \mathrm{F}
$$

Substitution of the expression for $F$ gives the Fokker-Planck equation, which becomes rather lengthy in the case with mass flow. When there is only diffusion it becomes:

$$
\frac{\partial \mathrm{C}}{\partial \mathrm{t}}=\mathrm{D}^{\prime}\left(\frac{\partial^{2} \mathrm{C}}{\partial \mathrm{r}^{2}}+\frac{1}{\mathrm{r}} \frac{\partial \mathrm{C}}{\partial \mathrm{r}}\right)
$$

where $\mathrm{D}^{\prime}=$ D.L. Note that $\Theta$ has cancelled out.

The initial and boundary conditions are:

$\mathrm{t}=0 \quad \mathrm{r}>\mathrm{R}, \quad \mathrm{C}=\mathrm{C}_{0}$

$t \geqslant 0 \quad \mathrm{r}=\mathrm{R}, \quad \mathrm{C}=0$

The inner cylinder with radius $\mathrm{R}$, or root, is thus regarded as a zero sink.

The analytical solution of this partial differential equation, with the above boundary and initial conditions, is given by Crank (1956, p. 82) and Carslaw \& Jaeger (1959, pp. 335-336) for the case where $C=C_{0}$ is constant at $r=\infty$. This solution can be used to check the numerical solution (de Wit \& van Keulen, 1972).

Although an analytical solution for the combined diffusive and convective flow is available (Olsen \& Kemper, 1968), it is very complicated and a numerical solution is more practical. The partial differential equation for this case is therefore not written out here.

The listing of a program to solve the radial flux equation numerically is given by de Wit $\&$ van Keulen (1972, Chap. 3). This makes it possible to calculate the depletion of anions in a finite zone around the roots. The zone is defined by giving $\mathbf{r}_{\max }$ a value, dividing the zone into concentric compartments and calculating the radial flux across each of the compartments and into the root. By changing the value of $r_{\max }$ the effect of distance between roots (or root density) on the radial flux under different flow conditions can be determined.

The radial flux is then integrated over time and the amount of anion removed expressed as a fraction of the original amount of anion in the defined root zone (see Appendix).

\section{Problem specifications}

Representation of the root zone as cylindrical means that the corners of the square columns into which a soil volume would be subdivided are neglected. To take the 
corners into account, $r_{\max }$ should be increased. A fair approximation should be $r_{\max } \vee(4 / \pi)$ or $1.13 r_{\max }$. The $r_{\max }$ values given below, therefore refer more accurately to the given root distances/1.13.

The radial flux equation was solved for the following conditions:

$$
\begin{aligned}
\mathrm{R} & =0.03 \mathrm{~cm} \\
\mathrm{r}_{\max } & =0.5 \mathrm{~cm}(1 \mathrm{~cm} \text { between roots) } \\
\mathrm{r}_{\operatorname{mix}} & =1.0 \mathrm{~cm}(2 \mathrm{~cm} \text { between roots) } \\
\mathrm{D}_{0} & =1.0 \mathrm{~cm} \text { (for loess soil) } \\
\mathrm{s} & =7.0 \mathrm{~cm} \text { (for clay and sand) }
\end{aligned}
$$

(these values are from Frissel et al., 1970).

$\mathrm{w}=0 \quad$ (no mass flow, diffusion only)

and $\mathrm{w}=0.025(2.5 \mathrm{~mm}$ transpiration day-1, roots $1 \mathrm{~cm}$ apart, $10 \mathrm{~cm} \mathrm{long})$ and $\mathrm{w}=0.050\left(5.0 \mathrm{~mm}\right.$ transpiration $\mathrm{day}^{-1}$, roots $1 \mathrm{~cm}$ apart, $10 \mathrm{~cm}$ long) where $w$ is water uptake per unit root length $\left(\mathrm{cm}^{3}\right.$ day-1 $\left.\mathrm{cm}^{-1}\right)$, related to $\mathrm{v}$ according to $\mathrm{w}=-2 \pi \mathrm{rv}$.

The values for $w$ are based on the assumptions that roots are evenly distributed $1 \mathrm{~cm}$ apart and their effective depth is $10 \mathrm{~cm}$. $w$ is then determined as the amount

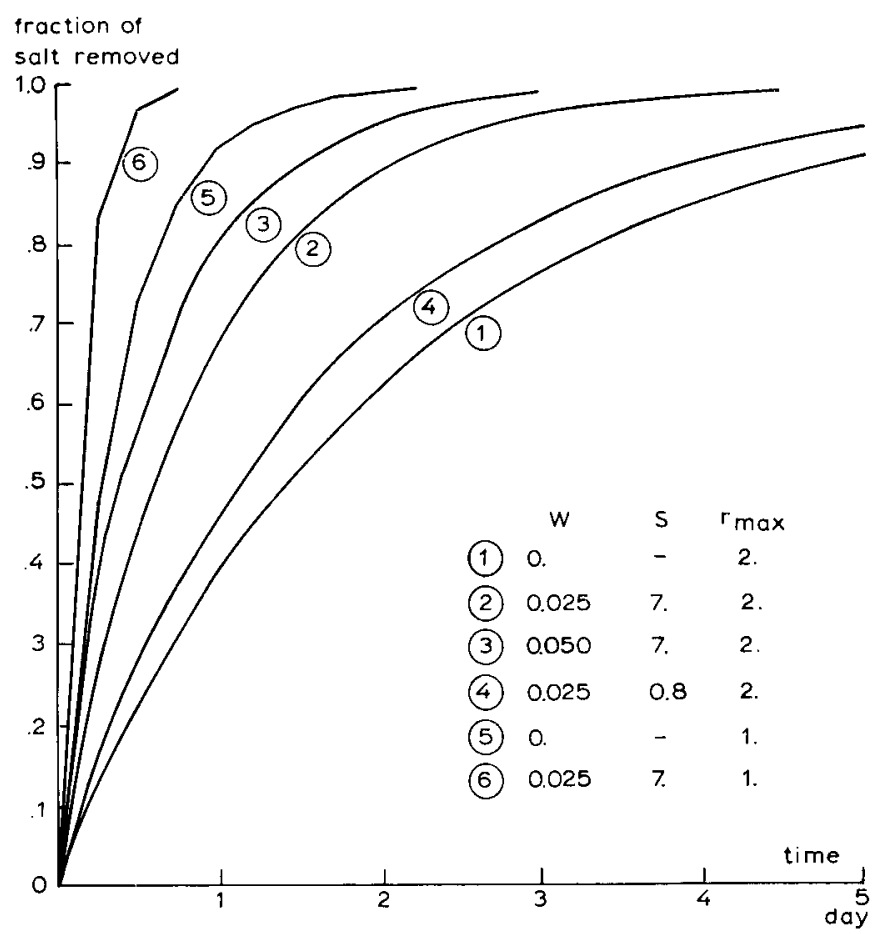

Fig. 1. Amount of anion removed from soil solution with different root densities, flow rates and dispersion factors. 
of water withdrawn from each $\mathrm{cm}^{3}$ of soil in the given root depth. When transpiration is $2.5 \mathrm{~mm} \mathrm{day}^{-1}$, then $\mathrm{w}=0.25 \mathrm{~cm}^{3}$ water $\left(10 \mathrm{~cm}^{3} \text { soil }\right)^{-1} \mathrm{day}^{-1}$, or $0.025 \mathrm{~cm}^{3}$ (cm length of root) ${ }^{-1}$ day $^{-1}$.

If effective rooting is increased, $w$ is decreased proportionately to maintain the same transpiration rates. When roots are $2 \mathrm{~cm}$ apart, the transpiration rate for a given value of $w$ is $1 / 4$ of the above rates.

Initial values of anion concentration were taken as $0.005 \mathrm{mmol} \mathrm{cm}^{3}$ water which is equivalent to $70 \mathrm{mg} \mathrm{N} / \mathrm{kg}$. It should however be noted that for the purposes of this study, the fraction of anion removed to a zero sink in the root was calculated and this result would have been unaffected by initial concentration. The absolute amount transported to the zero sink would then be directly proportional to concentration.

\section{Results}

Some results are given in Fig. 1. Depletion is slowest when root density is low ( 1 root per $4 \mathrm{~cm}^{2}$ ) and there is no mass flow. However, even here more than $90 \%$ of the anions are depleted within five days (curve 1). A slight mass flow, equivalent to a transpiration rate of $0.6 \mathrm{~mm}$ day $^{-1}$ reduces the time to arrive at a similar depletion level to just over two days in loess soil with a dispersion coefficient of 7 (curve 2), but only to four days in sand and clay soils with dispersion coefficients of around 0.8 (curve 4). Doubling the transpiration rate in a loess soil, adds very little to the rate of depletion (curve 3 ).

Increasing root density to 1 root $\mathrm{cm}^{-2}$, however, dramatically increases transport by diffusion to the extent that a similar depletion level is attained in less than one day (curve 5). In a loess soil with a transpiration rate of $2.5 \mathrm{~mm}^{\text {day }}{ }^{-1}$ similar depletion levels are attained in half the time (curve 6).

Thus anion transport can be increased considerably by mass flow especially when the dispersion coefficient of soils is high. For most soils with much lower dispersion coefficients than loess, transport must be mainly by diffusion, especially when the anion concentration in the soil solution is low.

In order to gauge the ecological significance of these results, the time scale of these processes should be noted. Depletion of $90 \%$ of the anions with a sparse root system within four days means that for actively growing plants virtually the whole anion store is available if they need it and this can be transported to the root by diffusion only. With a denser root system, virtually the whole anion store is potentially available in one day, again even by diffusion alone. This is particularly important in understanding nitrate uptake by growing plants and explains how nitrogen fertilizer can be so efficiently utilized even when the actual increase in concentration of the nitrate in the soil solution that is being taken up for transpiration is small.

When nitrogen is limiting growth, virtually all the nitrate will be taken up soon after it is released (by mineralization for instance). As a result the soil under a growing sward will have a very low nitrate concentration, as is so often found 
(Nye, 1969). However, this is not necessarily due to the supply being so low as much as it is due to the transport to (and into) the root being so rapid.

\section{Discussion}

Theoretical considerations of transport of anions to a root of an actively growing plant indicate that the anion store can be made readily available to the plant by diffusion only. The rate of depletion of a given anion by diffusion is dependent on the root density, the diffusion coefficient of the anion and the period during which the anion store must become available. It is not necessarily dependent on the moisture content of the soil because as soil moisture drops the anion concentration increases while diffusion continues even at low soil moisture levels (see 'Theoretical background'). A given density may be inadequate, if depletion must occur within a given period but it may be adequate if the permissable depletion period is longer; or if an anion with a larger diffusion coefficient is considered. The relationships between these factors can be represented as follows:

$$
\begin{aligned}
& \mathrm{RDN}=\mathrm{D}_{0} \cdot \mathrm{t} / \mathrm{X}^{2} \\
& \mathrm{RDN}=\text { a dimensionless root density number } \\
& \mathrm{X}=\text { distance between roots } / 1.13 \text { (see 'Problem specifica- } \\
& \begin{array}{ll}
\mathrm{D}_{0}= & \text { dions') }(\mathrm{cm}) \\
\mathrm{t}= & \text { time during which the anion store must become avail- } \\
& \text { able to supply the needs of the plant (day). }
\end{array}
\end{aligned}
$$

The value of RDN for which root density is adequate for depletion by diffusion can be determined by substituting the values obtained in this study. Both sets, $\mathrm{X}=1, \mathrm{D}_{0}=1, \mathrm{t}=1$ and $\mathrm{X}=2, \mathrm{D}_{0}=1 ., \mathrm{t}=4$ give an $\mathrm{RDN}$ value of 1 . Thus, when RDN $>1$ the root system is sufficiently dense to deplete the anion store by diffusion within the period $t$. When $\mathrm{RDN}<1$, the root density is too low to deplete the store in period $t$ by diffusion only. Mass transport will become more important in such a case.

It may be necessary for the root system to be dense enough to deplete the anion store in one day when supply is low but continuous. This would occur when nitrate is being released by micro-organisms during the growth period of a plant.

Micro-organisms that compete with the plant roots for the available anions will directly affect the availability of anions to the plant. As they are located between the roots where anion concentration is higer, it is reasonable to suppose that they will have first call on the available anions. Depending on their activity and the availability of anions, they can make the anion unavailable to the plant. In order to compete with micro-organisms for a small amount of anion, the root density must equal the density of the micro-organisms. Thus in the presence of strong competition from micro-organisms, the root density will be too low to supply the needs of the plant even when $\mathrm{RDN}=1$.

The number, RDN, can also be used to determine the adequacy of a given root density for water withdrawal from the soil. As the diffusion coefficient of water (diffusivity) depends on the moisture content of the soil, the adequacy of the root 
system will depend largely on the soil moisture content. For a moist soil, $\mathrm{D}_{\mathbf{0}}$ is much larger than 1 and the value drops to 1 only as the soil water potential approaches 4 to 5 atmospheres (Childs, 1969). Thus for most situations where the soil moisture is somewhat above the wilting point a root density that is adequate for supplying anions is also adequate for supplying water.

The availability to the plant of anions, and in drier conditions of water too, is thus dependent mainly on root density. As the root system responds to nutrient and sometimes even to water shortage by better growth (Brouwer \& de Wit, 1969) it will often increase its density when the need arises. It must therefore be concluded that in most cases of a normal, well developed root system, virtually the whole anion store in the rooting zone will be almost immediately available for plant growth. It would seem that a similar situation holds for water as long as soil moisture is not too low.

\section{Acknowledgment}

The authors are indebted to Prof. C. T. de Wit for the stimulating discussions and the provocative comments that initiated the ideas presented here.

\section{Appendix: Programming the numerical solution for the flow equation}

The core of the program given by de Wit \& van Keulen (1972, Chap. 3) consists of the following statements:

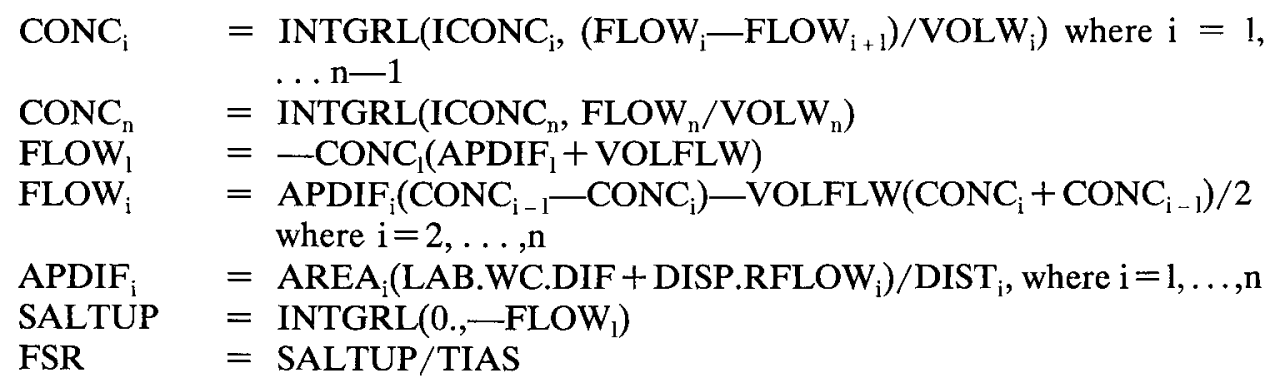

where:

n

$=$ number of concentric compartments into which the zone around the root is devided

$\mathrm{CONC}_{\mathrm{i}}=$ concentration of anion $\left(\mathrm{mmol} \mathrm{cm}^{-3}\right)$ in compartment

ICONC $_{\mathrm{i}}=$ initial concentration of anion in compartment $(\mathrm{mmol} \mathrm{cm}-3)$

FLOW $_{\mathrm{i}} \quad=$ flow of anion over a boundary (mmol day ${ }^{\mathbf{1}}$ )

VOLW $_{\mathrm{i}} \quad=$ volume of water in compartment $\left(\mathrm{cm}^{3}\right)$

APDIF $_{\mathrm{i}}=$ apparent diffusion coefficient for anion flow $\left(\mathrm{cm}^{3} \mathrm{day}^{-1}\right)$

VOLFLW $=$ volume of water flow $\left(\mathrm{cm}^{3} \mathrm{day}^{-1}\right)$

AREA $_{\mathrm{i}}=$ area of cylinder compartment $\left(\mathrm{cm}^{2}\right)$

LAB = labyrinth factor (dimensionless) 


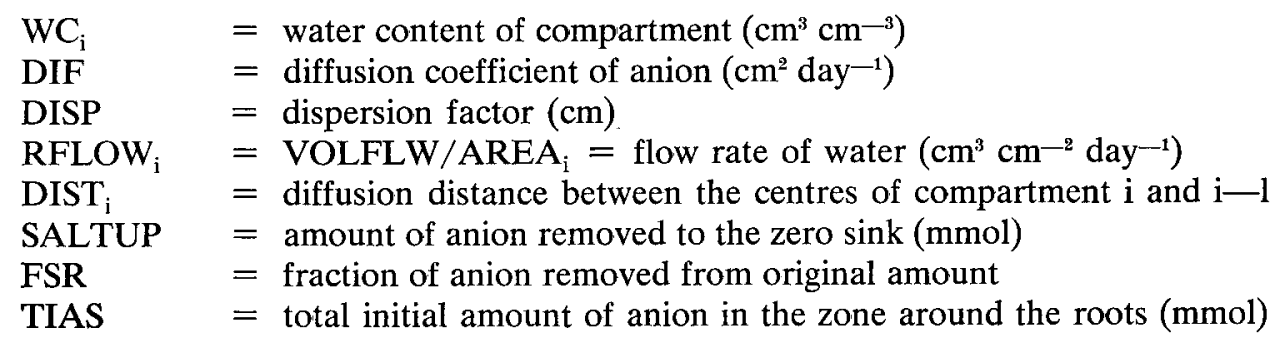

\section{References}

Brouwer, R. \& C. T. de Wit, 1969. A simulation model of plant growth with special attention to root growth and its consequences. In: W. J. Whittington (Ed.), Root growth, pp. 224-242, London.

Carlslaw, H. S. \& J. C. Jaeger, 1959. Conduction of heat in solids. Oxford University Press.

Childs, E. C., 1969. An introduction to the physical basis of soil water phenomena. John Wiley and Sons, London.

Crank, J., 1956. The mathematics of diffusion. Oxford University Press.

Frissel, M. J., P. Poelstra \& P. Reiniger, 1970. Chromatographic transport through soils. $P$ l. Soil 33: 161-176.

Jaeger, J. C., 1955. Numerical values for the temperature in radial heat flow. J. Math. Phys. 34: 316-321.

Nye, P. H., 1969. The soil model and its application to plant nutrition. In: I. H. Rorison (Ed.), Ecological aspects of the mineral nutrition of plants, pp. 105-114. Blackwell, London.

Olsen, S. R. \& W. D. Kemper, 1968. Movement of nutrients to plant roots. Adv. Agron. 20: 91-151.

Tinker, P. B., 1969. The transport of ions in the soil around plant roots. In: I. H. Rorison (Ed.), Ecological aspects of mineral nutrition of plants, pp. 135-148. Blackwell, London.

Wit, C. T. de \& H. van Keulen, 1972. Simulation of transport processes in soils. Pudoc, Wageningen. 